\title{
Impacto do código florestal e da lei da Mata Atlântica em áreas de mata ciliar de propriedades rurais do Estado de Santa Catarina
}

Impact of the forest code and the Atlantic Forest law on riparian forest areas of rural properties in

\author{
the Santa Catarina State
}

Impacto del código forestal y la Ley de la Mata Atlántica en las áreas forestales de ribera de propiedades rurales en el Estado de Santa Catarina

Recebido: 21/01/2021 | Revisado: 24/01/2021 | Aceito: 30/01/2021 | Publicado: 07/02/2021

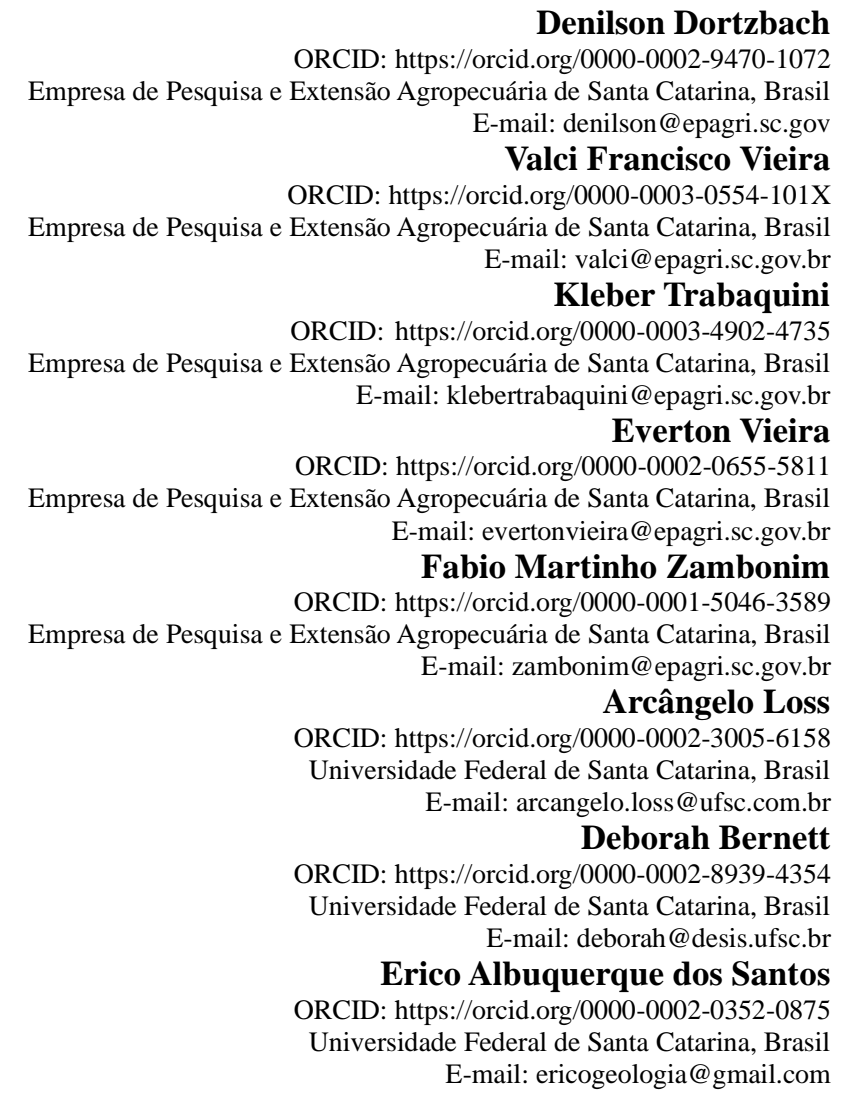

\section{Resumo}

O estado de Santa Catarina encontra-se inserido no Bioma Mata Atlântica, ecossistema no qual a aplicação da legislação ambiental tem sido objeto de intensas discussões técnico-jurídicas. Este estudo objetivou avaliar os impactos da aplicação do Código Florestal (CF) e da Lei da Mata Atlântica (LMA) sobre as áreas de mata ciliar em propriedades rurais de Santa Catarina. Foram avaliadas 100 propriedades rurais e os resultados demonstraram que pelo menos $65 \%$ dessas propriedades atendem os requisitos de Reserva Legal, que para o estado é definido em $20 \%$. Com a aplicação do CF, observa-se que em 77 propriedades, as áreas de mata ciliar ocupam menos de $10 \%$ da área total da propriedade. Já com a aplicação da LMA, esse número cai para 24 propriedades. Com o cruzamento das informações da área produtiva das propriedades rurais e a área de produção dentro da área de mata ciliar, os resultados mostram que aplicando o CF, 80 propriedades apresentam redução da área produtiva em até $10 \%$. Para o valor de perda da área produtiva de até $20 \%$, o número de propriedades chega a 95 . Com a aplicação da LMA, a perda em até $10 \%$ da área produtiva cai para 16 propriedades. Com a aplicação desta lei, $55 \%$ das propriedades tem redução de área produtiva superior a $20 \%$. A aplicação das legislações traz impactos diferenciados sobre as propriedades rurais, sendo que a LMA tem caráter maior de preservação ambiental e, consequentemente, impacta mais fortemente na diminuição das áreas produtivas.

Palavras-chave: Área de preservação permanente; Legislação ambiental; Uso do solo; Reserva legal. 


\begin{abstract}
The Santa Catarina state is inserted in the Atlantic Forest Biome, an ecosystem in which the application of environmental legislation has been the subject of intense technical-legal discussions. This study aimed to evaluate the impacts of applying the Forest Code $(\mathrm{CF})$ and the Atlantic Forest Law (LMA) on riparian forest areas in rural properties in Santa Catarina. 100 rural properties were evaluated and the results showed that at least $65 \%$ of these properties meet the requirements of Legal Reserve, which for the state is defined at $20 \%$. With the CF application, it's observed that in 77 properties, the riparian forest areas occupy less than $10 \%$ of the total area of the property. With the LMA application, this number drops to 24 properties. With the crossing of information from the productive area of rural properties and the production area within the riparian forest area, the results show that by applying the $\mathrm{CF}, 80$ properties show a reduction in the productive area by up to $10 \%$. For the value of loss of the productive area of up to $20 \%$, the number of properties reaches 95 . With the LMA application, the loss of up to $10 \%$ of the productive area drops to 16 properties. With the application of this law, 55\% of the properties have a production area reduction greater than $20 \%$. The application of laws brings different impacts on rural properties, with the LMA having a greater character of environmental preservation and, consequently, impacts more strongly in the reduction of productive areas.
\end{abstract}

Keywords: Permanent preservation area; Environmental legislation; Soil use; Legal reserve.

\title{
Resumen
}

El estado de Santa Catarina se inserta en el Bioma Mata Atlántica, ecosistema en que la aplicación de la legislación ambiental ha sido objeto de intensas discusiones técnicas-legales. Este estudio evaluó los impactos de la aplicación del Código Forestal (CF) y la Ley del Bosque Atlántico (LMA) en áreas de bosque de ribera (BR) en propiedades rurales de Santa Catarina. Se evaluaron 100 propiedades rurales y los resultados mostraron que 65\% de estas propiedades cumplen con los requisitos de Reserva Legal, que para el estado se define en $20 \%$. Con la aplicación del CF, se observa que en 77 propiedades, las áreas de BR ocupan menos del 10\% del área total de la propiedad. Con la aplicación de LMA, este número cae a 24 propiedades. Con el cruce de información del área productiva de predios rurales y el área de producción dentro del área de BR, los resultados muestran que al aplicar el CF, 80 predios muestran una reducción del área productiva de hasta 10\%. Para el valor de pérdida del área productiva de hasta $20 \%$, el número de predios llega a 95. Con la aplicación del LMA, la pérdida de hasta $10 \%$ del área productiva desciende a 16 predios. Con la aplicación de esta ley, el 55\% de las propiedades tienen una reducción de área de producción superior al 20\%. La aplicación de las leyes trae diferentes impactos en las propiedades rurales, teniendo la LMA un mayor carácter de preservación ambiental y, en consecuencia, impactos más fuertes en la reducción de áreas productivas.

Palabras clave: Área de conservación permanente; Legislación medioambiental; Uso del suelo; Reserva legal.

\section{Introdução}

O estado de Santa Catarina encontra-se inserido no Bioma Mata Atlântica, onde coexistem os sistemas jurídicos regulados pelo Código Florestal e pela Lei da Mata Atlântica. A aplicabilidade do Código Florestal, Lei N ${ }^{\circ}$ 12.651/2012 (BRASIL, 2012) tem sido objeto de intensas discussões técnico-jurídicas, principalmente pelo fato de que há, no Brasil, a Lei N 11.428/2006 (BRASIL, 2006), conhecida por Lei da Mata Atlântica, que versa sobre a proteção deste bioma.

O Supremo Tribunal Federal (STF) julgou constitucionais os artigos 61-A e 61-B do Código Florestal, que permitem a continuidade de atividades de baixo impacto e estabelecem critérios para a recomposição das áreas de proteção permanente (APP). Entretanto, essa determinação tem sido contestada, com o argumento de que a Lei 11.428/2006 impediria a consolidação de áreas de preservação permanentes (APPs) situadas na Mata Atlântica, pelo fato de se tratar de uma lei mais antiga (STF, 2020).

O principal ponto discutido está na possibilidade de manutenção das atividades agrossilvipastoris, de ecoturismo e de turismo rural em APPs inseridas em áreas rurais consolidadas até 22 de julho de 2008 (BRASIL, 2012). É importante destacar que o estado de Santa Catarina vem apresentando um aumento gradativo nos últimos anos na sua área de floresta. Essa informação pode ser observada na Série Anual de Mapas de Cobertura e Uso de Solo desenvolvido pelo MapBiomas, realizado no período de 1985 a 2018, na escala 1:100.000, produzido através da análise de imagens de satélites Landsat com resolução de 30 metros (MapBiomas, 2020). No ano de 2008, a classe de uso do solo com Floresta representava 52,66\% do estado e passou para 54,33\% no ano de 2018. Neste período foram convertidos 159.793 hectares em áreas de florestas, provenientes de áreas ocupadas anteriormente pela agricultura e pastagens (MapBiomas, 2020). 
Estas alterações estão relacionadas tanto pelas condições físicas diferenciadas do estado de Santa Catarina, assim como pelos reflexos relacionados ao êxodo rural e ao envelhecimento da população rural, que deixam de produzir em áreas de maior declividade, e em poucos anos estas se convertem em florestas secundárias (Freitas, 2013). É importante destacar a configuração latifundiária do estado, composta de pequenas propriedades rurais, e que medidas ambientais podem apresentar impactos significativamente diferenciados para estas condições específicas, especialmente quando são sobrepostas a geomorfologia (condições de relevo e drenagem).

Neste sentido, são necessários estudos que possam contribuir com informações concretas relacionadas aos reflexos da aplicação das distintas legislações e seus impactos econômicos e ambientais, principalmente relacionados aos pequenos produtores rurais. Assim, o objetivo do presente estudo foi avaliar os impactos da aplicação do Código Florestal (Lei $\mathrm{n}^{\circ}$ 12.651/2012) e da Lei da Mata Atlântica (Lei n. 11.428/06) sobre as APPs, especificamente nas áreas de mata ciliar, em propriedades rurais do estado de Santa Catarina distribuídas em diferentes regiões do estado.

\section{Metodologia}

O estudo foi realizado em 100 propriedades rurais localizadas em cinco municípios de diferentes regiões do estado de Santa Catarina, conforme destacado na Figura 1. Todas as imagens foram processadas em sistema de informação geográfica. A metodologia usada neste estudo é de natureza qualiquantitativa (Pereira et al., 2018). Os municípios selecionados foram Barra Bonita e Guarujá do Sul, ambos localizados na região Extremo-Oeste do estado; Luzerna, localizado na região do Meio Oeste Catarinense; Lontras, localizado na região do Alto Vale do Itajaí e Papanduva, na região do Planalto Norte Catarinense (Figura 1). 
Figura 1. Distribuição espacial dos municípios que contém as propriedades rurais avaliadas no estudo.



Fonte: Autores.

As propriedades rurais avaliadas com seus devidos módulos fiscais são apresentadas na Tabela 1.

Tabela 1. Propriedades rurais avaliadas, com destaque para os respectivos módulos fiscais.

\begin{tabular}{|c|c|c|c|c|c|c|}
\hline \multirow{2}{*}{ Municípios } & \multirow{2}{*}{ Número de propriedades } & \multirow{2}{*}{ Tamanho do módulo fiscal } & \multicolumn{3}{|c|}{ Módulo Fiscal } & \multirow[b]{2}{*}{ acima de 4} \\
\hline & & & até 1 & de 1 a 2 & de 2 a 4 & \\
\hline Barra Bonita & 24 & 20 & 14 & 9 & 1 & 0 \\
\hline Guarujá do Sul & 24 & 20 & 20 & 3 & 1 & 0 \\
\hline Lontras & 18 & 18 & 8 & 9 & 1 & 0 \\
\hline Luzerna & 8 & 20 & 3 & 4 & 1 & 0 \\
\hline Papanduva & 26 & 16 & 15 & 4 & 2 & 5 \\
\hline TOTAL & 100 & 94 & 60 & 29 & 6 & 5 \\
\hline
\end{tabular}

Fonte: Autores.

As propriedades foram selecionadas de forma aleatória, sendo que em todas foram desenvolvidos trabalhos dentro do Projeto Aptidão por Demanda, desenvolvido pela equipe da Empresa de Pesquisa e Extensão Rural de Santa Catarina (Epagri/CNPq, 2013) e, entre um dos seus objetivos, estava à delimitação participativa das propriedades rurais, conforme exemplo apresentado na Figura 2. 
Figura 2. Limite de uma propriedade em Guarujá do Sul, SC, na área de estudo.

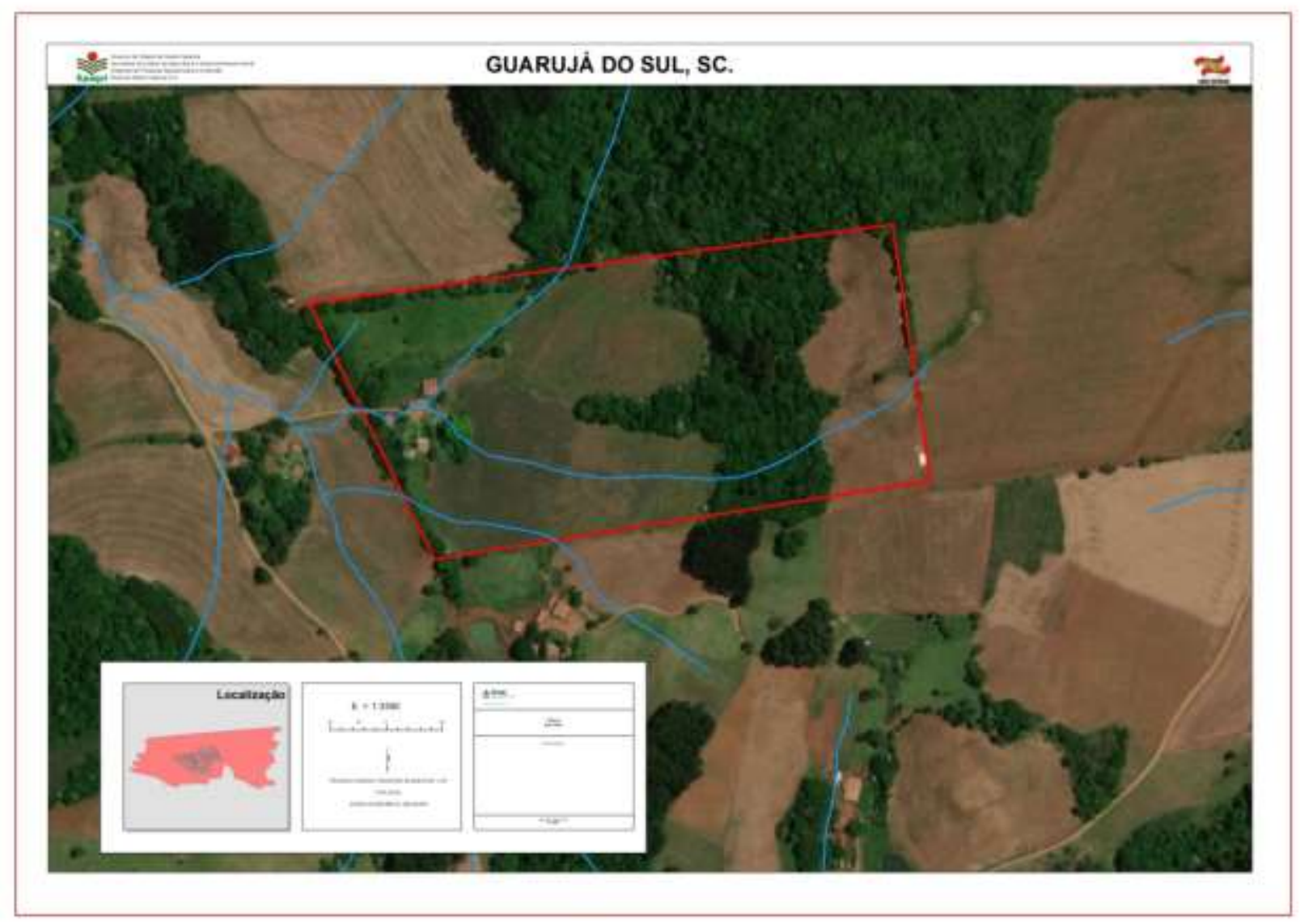

Fonte: Autores.

Com as áreas delimitadas foi realizado o mapeamento de uso do solo de todas as propriedades através da utilização de fotografias aéreas na escala de 1:10.000 do aerolevantamento fotográfico de Santa Catarina (SDS/SC, 2010). Para análise do uso da terra, o método foi estruturado a partir da visão sinóptica da área utilizando as fotografias aéreas, ortorretificadas, com resolução espacial de $1 \mathrm{~m}$. O processamento digital das imagens foi realizado no software ArcGIS® 10.6, da Esri.

As classes definidas para o presente estudo foram de floresta e não floresta (Figura 3), sendo que esta última classe abrange todos os demais usos do solo. Reflorestamentos foram incluídos em áreas de não floresta. Importante destacar que o presente estudo não avaliou a qualidade das referidas áreas que compõem a classe floresta (Figura 3). 
Research, Society and Development, v.10, n.2, e10910212251, 2021

(CC BY 4.0) |ISSN 2525-3409 | DOI: http://dx.doi.org/10.33448/rsd-v10i2.12251

Figura 3. Uso e cobertura do solo em uma propriedade em Guarujá do Sul, SC, na área de estudo.



Fonte: Autores.

As áreas de mata ciliar foram identificadas através da utilização da rede de drenagem retificadas das fotografias aéreas de 2010 (SDS/SC, 2010), gerando buffers conforme o Código Florestal e a Lei da Mata Atlântica (Figura 4). 
Figura 4. Faixa de mata ciliar conforme legislação em uma propriedade rural.

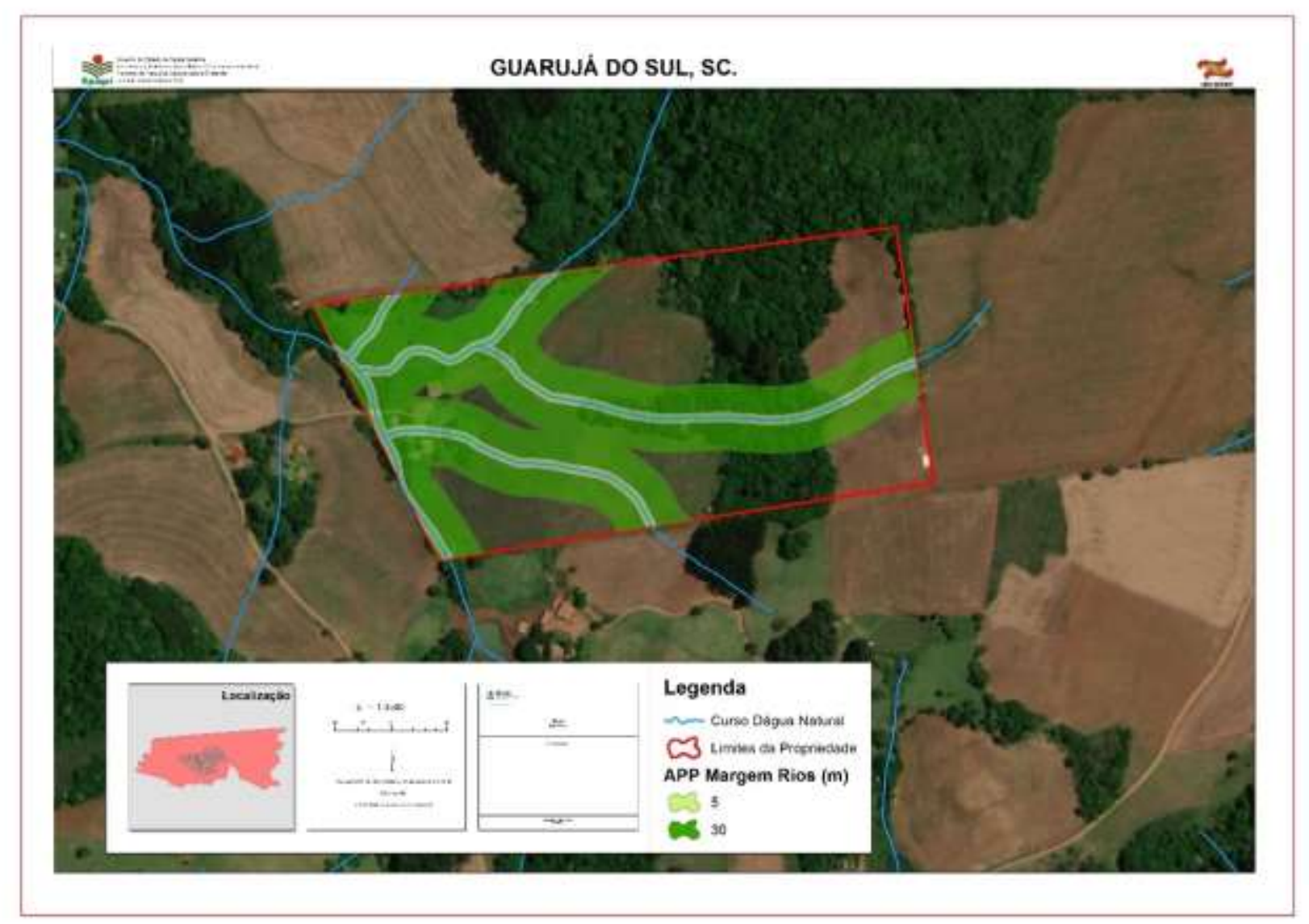

Fonte: Autores.

Os dados do uso do solo foram cruzados com os buffers de mata ciliar, de acordo com a legislação relacionada. A APP é uma área protegida, coberta ou não por vegetação, com a função ambiental de preservar os recursos hídricos, a paisagem, a estabilidade geológica e a biodiversidade, facilitar o fluxo gênico de fauna e flora, proteger o solo e assegurar o bem-estar das populações humanas.

As APPs não foram tratadas pela Lei da Mata Atlântica e se configuram em casos de aplicação subsidiária da Lei $n^{\circ}$ 4.771/1965 (BRASIL, 1965), posteriormente revogada pela Lei $n^{\circ}$ 12.651/2012 (BRASIL, 2012). Esta última ao tratar das APP, abordou de duas formas distintas: a primeira foi o estabelecimento do regime geral a elas aplicável utilizada pela Lei da Mata Atlântica (Tabela 2) e a segunda foi o estabelecimento de normas transitórias para as chamadas APPs consolidadas, que não são áreas de preservação permanente, pelo contrário, atividades que, em tese, nelas não poderiam ser exercidas legalmente. Assim, a norma reconhece uma situação de fato que se consolidou em contravenção à lei e neste sentido não utilizadas pela Lei da Mata Atlântica (Antunes, 2020). 
Tabela 2. Faixa de APP conforme a largura dos cursos d'agua perenes e intermitentes.

\begin{tabular}{lc}
\hline Largura do Rio $(\mathbf{m})$ & Faixa de APP $(\mathbf{m})^{*}$ \\
\hline Até 10 & 30 \\
$10-50$ & 50 \\
$50-200$ & 100 \\
$200-600$ & 200 \\
Acima de 500 & 600 \\
\hline
\end{tabular}

Fonte: Autores.

No Código Florestal (Brasil, 2012) em área rural consolidada com atividades agrossilvipastoris é permitida a continuidade destas atividades. Entretanto, há a necessidade de se recuperar uma faixa mínima da APP de acordo com o tamanho do imóvel rural, conforme detalhado na Tabela 3.

Tabela 3. APPs de cursos d'agua em áreas rurais consolidadas.

\begin{tabular}{ccc}
\hline $\begin{array}{c}\text { Tamanho do imóvel rural (módulos } \\
\text { fiscais) }\end{array}$ & Faixa de recomposição da APP $(\mathbf{m})$ & Área máxima de APP \\
\hline Até 1 & 5 & $10 \%$ da Propriedade \\
1 a 2 & 8 & $10 \%$ da Propriedade \\
2 a 4 & 15 & $20 \%$ da Propriedade \\
\hline
\end{tabular}

Fonte: Autores.

Para imóveis rurais com área superior a 4 módulos fiscais, será obrigatória a recomposição das respectivas faixas marginais, conforme determinação do Programa de Recuperação Ambiental (PRA), observado o mínimo de vinte metros, contados da borda da calha do leito regular, para imóveis com área superior a quatro e de até dez módulos fiscais, nos cursos d'água com até dez metros de largura; e nos demais casos, extensão correspondente à metade da largura do curso d'água, observado o mínimo de trinta e o máximo de cem metros, contados da borda da calha do leito regular (BRASIL, 2012).

\section{Resultados e Discussão}

$\mathrm{Na}$ Tabela 4 são apresentadas as faixas de área ocupadas por floresta nos diferentes municípios. Observa-se que em 35 propriedades, a área florestal ocupa menos de $20 \%$ da área total.

Tabela 4. Número de propriedades rurais com porcentagem de uso com floresta.

\begin{tabular}{lcccccc}
\hline \multirow{2}{*}{ Municípios } & \multicolumn{5}{c}{ Percentual de área ocupada por floresta } \\
\cline { 2 - 6 } & $\mathbf{0 - 1 0 \%}$ & $\mathbf{1 0 - 2 0 \%}$ & $\mathbf{2 0 - 3 0 \%}$ & $\mathbf{3 0 - 4 0 \%}$ & $\mathbf{4 0 - 5 0 \%}$ & $>\mathbf{5 0 \%}$ \\
\hline Barra Bonita & 4 & 5 & 5 & 4 & 2 & 4 \\
Guarujá do Sul & 3 & 6 & 11 & 2 & 2 & 0 \\
Lontras & 1 & 4 & 5 & 2 & 3 & 0 \\
Luzerna & 2 & 2 & 5 & 5 & 1 & 7 \\
Papanduva & 3 & 5 & 28 & 14 & 9 & 14 \\
\hline TOTAL & 13 & 22 &
\end{tabular}

Fonte: Autores.

Esses dados mostram que pelo menos $65 \%$ das propriedades rurais atendem os requisitos de Reserva Legal, que para o estado de Santa Catarina é definido em 20\%. Importante salientar que não foi intuito deste estudo a avaliação da Reserva Legal nas propriedades rurais, porém as informações de uso com floresta podem indicar as propriedades rurais que estão 
adequadamente constituídas. Importante também destacar que não foi avaliado neste estudo, se ocorre alguma compensação de áreas de Reserva Legal em outras áreas.

O atual Código Florestal define a Reserva Legal como:

Art. $3^{\circ}$ Para os efeitos desta Lei, entende-se por:

(...)

III - Reserva Legal: área localizada no interior de uma propriedade ou posse rural, delimitada nos termos do art. 12, com a função de assegurar o uso econômico de modo sustentável dos recursos naturais do imóvel rural, auxiliar a conservação e a reabilitação dos processos ecológicos e promover a conservação da biodiversidade, bem como o abrigo e a proteção de fauna silvestre e da flora nativa (Brasil, 2012).

$\mathrm{Na}$ Tabela 5 são apresentados os percentuais equivalentes das áreas ocupadas pela mata ciliar nas propriedades rurais através da aplicação do Código Florestal. Observa-se que 77 propriedades rurais têm área inferior a 10\% destinadas a serem ocupadas por mata ciliar dentro das propriedades, segundo a legislação.

Tabela 5. Percentual de área ocupada por mata ciliar através da aplicação do Código Florestal.

\begin{tabular}{|c|c|c|c|c|c|}
\hline \multirow{2}{*}{ Municípios } & \multicolumn{5}{|c|}{ Percentual de área ocupada por mata ciliar } \\
\hline & $<5 \%$ & $5-10 \%$ & $10-20 \%$ & $20-30 \%$ & $>30 \%$ \\
\hline Barra Bonita & 8 & 9 & 5 & 0 & 2 \\
\hline Guarujá do Sul & 11 & 11 & 2 & 0 & 0 \\
\hline Lontras & 7 & 7 & 3 & 1 & 0 \\
\hline Luzerna & 5 & 3 & 0 & 0 & 0 \\
\hline Papanduva & 7 & 9 & 7 & 3 & 0 \\
\hline TOTAL & 38 & 39 & 17 & 4 & 2 \\
\hline
\end{tabular}

Fonte: Autores.

Já com a aplicação da Lei da Mata Atlântica, 44 propriedades têm mais de $30 \%$ da área total de suas propriedades destinadas a ocupação com mata ciliar (Tabela 6).

Tabela 6. Percentual de área ocupada por mata ciliar através da aplicação da Lei da Mata Atlântica.

\begin{tabular}{|c|c|c|c|c|c|}
\hline \multirow{2}{*}{ Municípios } & \multicolumn{5}{|c|}{ Percentual de área ocupada por mata ciliar } \\
\hline & $<5 \%$ & $5-10 \%$ & $10-20 \%$ & $20-30 \%$ & $>\mathbf{3 0} \%$ \\
\hline Barra Bonita & 2 & 3 & 6 & 5 & 8 \\
\hline Guarujá do Sul & 1 & 2 & 9 & 5 & 7 \\
\hline Lontras & 0 & 0 & 3 & 4 & 11 \\
\hline Luzerna & 1 & 0 & 3 & 4 & 0 \\
\hline Papanduva & 2 & 1 & 2 & 3 & 18 \\
\hline TOTAL & 6 & 6 & 23 & 21 & 44 \\
\hline
\end{tabular}

Fonte: Autores.

Observa-se que nas áreas de mata ciliar definidas de acordo com o previsto pelo Código Florestal, a ocupação com florestas é variada entre os municípios e pode ser considerada baixa. Do total, 49 propriedades possuem ocupação com florestas nas áreas de mata ciliar inferior a 50\%. Onze propriedades apresentaram ocupação entre 90 e 100\% (Tabela 7). Estes resultados mostram que existe a necessidade dos produtores realizarem a recomposição destas áreas, porém, a legislação não estipulou prazo para a realização desta ação. 
Tabela 7. Faixa percentual de floresta em área de mata ciliar, em 100 propriedades rurais do estado de Santa Catarina, com a aplicação do Código Florestal.

\begin{tabular}{lcccccccccc}
\hline Municípios & $\mathbf{0 - 1 0} \%$ & $\mathbf{1 0 - 2 0 \%}$ & $\mathbf{2 0 - 3 0 \%}$ & $\mathbf{3 0 - 4 0 \%}$ & $\mathbf{4 0 - 5 0 \%}$ & $\mathbf{5 0 - 6 0 \%}$ & $\mathbf{6 0 - 7 0 \%}$ & $\mathbf{7 0 - 8 0 \%}$ & $\mathbf{8 0 - 9 0 \%}$ & $\mathbf{9 0 - 1 0 0 \%}$ \\
\hline Barra Bonita & 3 & 1 & 4 & 6 & 2 & 4 & 1 & 0 & 0 & 3 \\
Guarujá do Sul & 1 & 0 & 1 & 3 & 3 & 3 & 3 & 4 & 2 & 4 \\
Lontras & 3 & 2 & 1 & 0 & 2 & 6 & 3 & 1 & 0 & 0 \\
Luzerna & 2 & 2 & 0 & 0 & 1 & 3 & 0 & 0 & 0 & 0 \\
Papanduva & 1 & 3 & 2 & 2 & 4 & 3 & 5 & 0 & 2 & 4 \\
\hline TOTAL & 10 & 8 & 8 & 11 & 12 & 19 & 12 & 5 & 4 & 11 \\
\hline
\end{tabular}

Fonte: Autores.

Se considerarmos a aplicação da Lei da Mata Atlântica, as áreas de mata ciliar ocupadas com floresta apresentam valores ainda inferiores em comparação com o Código Florestal, sendo que 77 propriedades apresentaram valores inferiores a $50 \%$ da área total mapeada. Destas, 31 apresentaram composição de floresta na mata ciliar de até $20 \%$ do total (Tabela 8).

Tabela 8. Faixa percentual de floresta em área de mata ciliar, em 100 propriedades rurais do estado de Santa Catarina, com a aplicação da Lei da Mata Atlântica.

\begin{tabular}{lcccccccccc}
\hline Municípios & $\mathbf{0 - 1 0 \%}$ & $\mathbf{1 0 - 2 0 \%}$ & $\mathbf{2 0 - 3 0 \%}$ & $\mathbf{3 0 -} \mathbf{4 0 \%}$ & $\mathbf{4 0 - 5 0 \%}$ & $\mathbf{5 0 - 6 0 \%}$ & $\mathbf{6 0 - 7 0 \%}$ & $\mathbf{7 0 - 8 0 \%}$ & $\mathbf{8 0 - 9 0 \%}$ & $\mathbf{9 0 - 1 0 0 \%}$ \\
\hline Barra Bonita & 3 & 4 & 3 & 3 & 2 & 3 & 3 & 1 & 0 & 2 \\
Guarujá do Sul & 6 & 7 & 5 & 2 & 3 & 1 & 0 & 0 & 0 & 0 \\
Lontras & 2 & 2 & 3 & 3 & 5 & 1 & 2 & 0 & 0 & 0 \\
Luzerna & 3 & 1 & 1 & 0 & 2 & 1 & 0 & 0 & 0 & 0 \\
Papanduva & 1 & 2 & 8 & 4 & 2 & 3 & 2 & 2 & 1 & 1 \\
\hline TOTAL & 15 & 16 & 20 & 12 & 14 & 9 & 7 & 3 & 1 & 3 \\
\hline
\end{tabular}

Fonte: Autores.

A avaliação do percentual de mata ciliar ocupada por floresta através da aplicação das duas legislações é apresentada na Figura 5. Observa-se que é baixo o percentual de áreas com 100\% de ocupação de floresta nas áreas de mata ciliar. 
Figura 5. Percentual de mata ciliar ocupada por floresta através da aplicação do Código Florestal e Lei da Mata Atlântica.

\section{\% DE MATA CILIAR COBERTA POR FLORESTA}

\section{5}

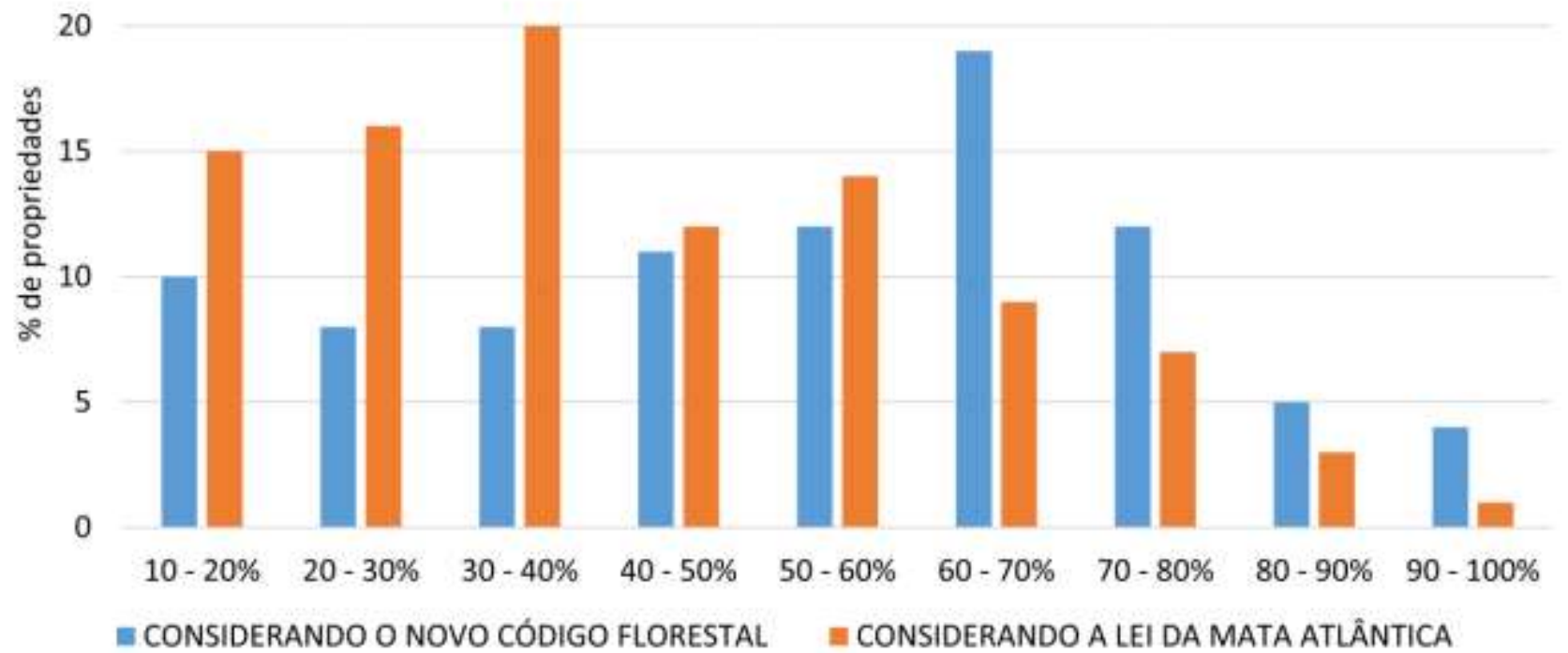

Fonte: Autores.

Com o cruzamento das informações da área produtiva das propriedades rurais e a área de produção dentro da área de mata ciliar (Tabela 9), de acordo com as duas legislações, os resultados mostram que aplicando o Código Florestal, 80 propriedades têm redução da área produtiva em até 10\%. Para o valor de perda da área produtiva de até $20 \%$, o número de propriedades vai para 95 .

Tabela 9. Faixa percentual de perda de área produtiva em 100 propriedades rurais do estado de Santa Catarina, com a aplicação do Código Florestal.

\begin{tabular}{lcccccccccc}
\hline Municípios & $\mathbf{0 - 1 0 \%}$ & $\mathbf{1 0 - 2 0 \%}$ & $\mathbf{2 0 - 3 0 \%}$ & $\mathbf{3 0 - 4 0 \%}$ & $\mathbf{4 0 - 5 0 \%}$ & $\mathbf{5 0 - 6 0 \%}$ & $\mathbf{6 0 - 7 0 \%}$ & $\mathbf{7 0 - 8 0 \%}$ & $\mathbf{8 0 - 9 0 \%}$ & $\mathbf{9 0 - 1 0 0 \%}$ \\
\hline Barra Bonita & 15 & 7 & 0 & 1 & 0 & 1 & 0 & 0 & 0 & 0 \\
Guarujá do Sul & 24 & 0 & 0 & 0 & 0 & 0 & 0 & 0 & 0 & 0 \\
Lontras & 14 & 3 & 0 & 1 & 0 & 0 & 0 & 0 & 0 & 0 \\
Luzerna & 8 & 0 & 0 & 0 & 0 & 0 & 0 & 0 & 0 & 0 \\
Papanduva & 19 & 5 & 1 & 1 & 0 & 0 & 0 & 0 & 0 & 0 \\
\hline \multicolumn{1}{c}{ TOTAL } & 80 & 15 & 1 & 3 & 0 & 1 & 0 & 0 & 0 & 0 \\
\hline
\end{tabular}

Fonte: Autores.

Com a aplicação da Lei da Mata Atlântica a perda em até $10 \%$ da área produtiva cai para 16 propriedades (16\%). Com a aplicação desta lei, 55\% das propriedades tem redução de área produtiva superior a 20\% (Tabela 10). 
Tabela 10. Faixa percentual de perda de área produtiva em 100 propriedades rurais do estado de Santa Catarina, com a aplicação da Lei da Mata Atlântica.

\begin{tabular}{lcccccccccc}
\hline \multicolumn{1}{c}{ Municípios } & $\mathbf{0 - 1 0} \%$ & $\mathbf{1 0 - 2 0 \%}$ & $\mathbf{2 0 - 3 0 \%}$ & $\mathbf{3 0 - 4 0 \%}$ & $\mathbf{4 0 - 5 0 \%}$ & $\mathbf{5 0 - 6 0 \%}$ & $\mathbf{6 0 - 7 0 \%}$ & $\mathbf{7 0 - 8 0 \%}$ & $\mathbf{8 0 - 9 0 \%}$ & $\mathbf{9 0 - 1 0 0 \%}$ \\
\hline Barra Bonita & 6 & 6 & 4 & 2 & 2 & 3 & 1 & 0 & 0 & 0 \\
Guarujá do Sul & 5 & 10 & 5 & 3 & 1 & 0 & 0 & 0 & 0 & 0 \\
Lontras & 0 & 4 & 6 & 4 & 3 & 1 & 0 & 0 & 0 & 0 \\
Luzerna & 1 & 5 & 2 & 0 & 0 & 0 & 0 & 0 & 0 & 0 \\
Papanduva & 4 & 4 & 2 & 8 & 2 & 4 & 0 & 0 & 2 & 0 \\
\hline TOTAL & 16 & 29 & 19 & 17 & 8 & 8 & 1 & 0 & 2 & 0 \\
\hline
\end{tabular}

Fonte: Autores.

Na Figura 6 é apresentada a comparação das duas legislações, demonstrando os impactos do percentual de área produtiva, reforçando que a Lei da Mata Atlântica impacta mais fortemente na área produtiva dos produtores rurais catarinenses.

Figura 6. Comparação do Código Florestal e Lei da Mata Atlântica, nos impactos do percentual de área produtiva.

\section{REDUÇÃO DA ÁREA PRODUTIVA}

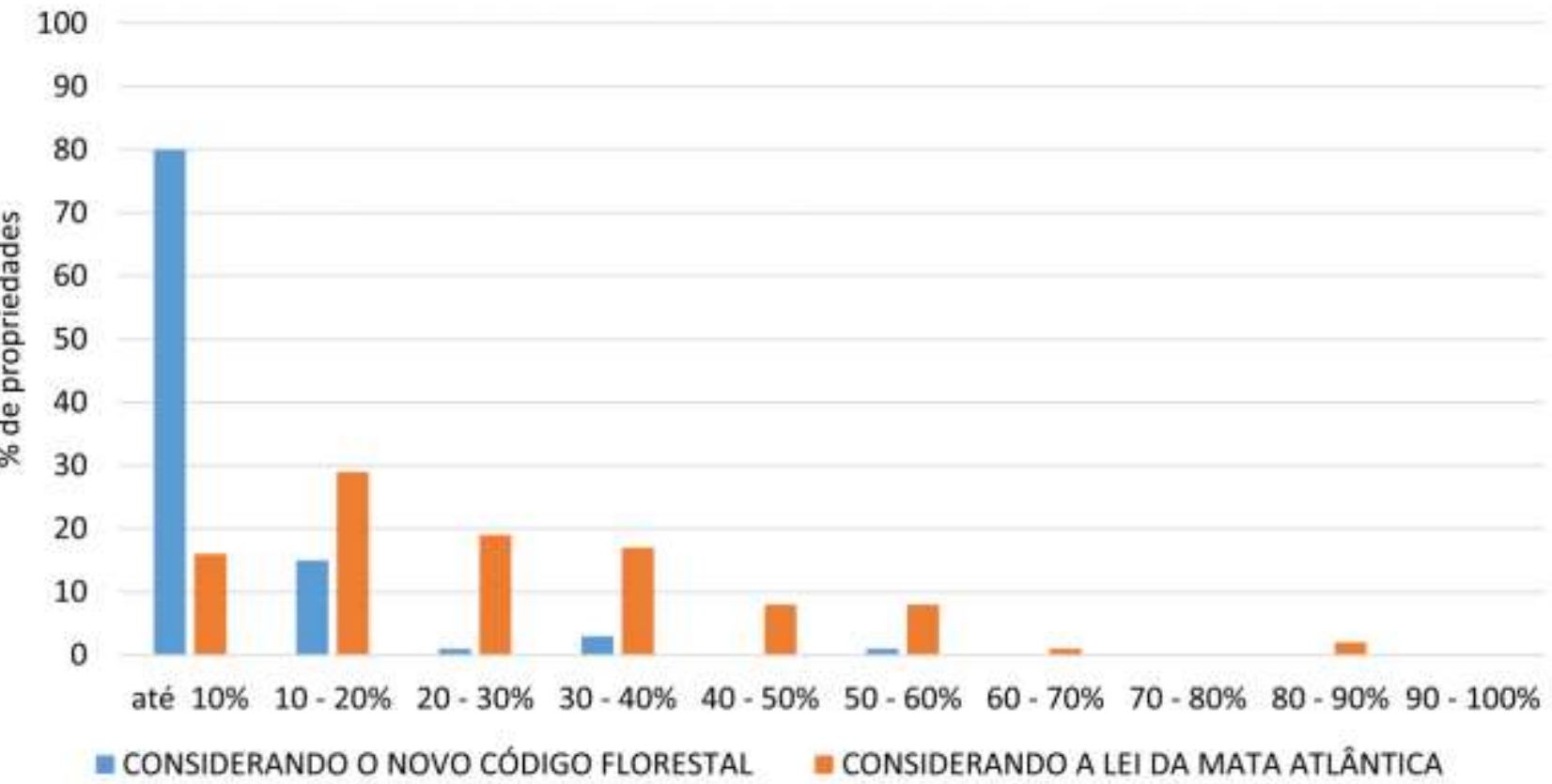

Fonte: Autores.

Segundo Passos e Klock (2019), o equilíbrio ambiental depende do desenvolvimento sustentável, sendo importante áreas como as APPs e as RLs, visto que são áreas com destaque para o meio ecológico, uma vez que possuem espécies nativas, endêmicas e que garantem a sustentabilidade da agricultura em longo prazo. Entretanto, ainda faz-se necessário avaliar a relação entre produtores rurais e proteção de áreas ambientais, pois o equilíbrio homem-natureza é necessário para que tenhamos o desenvolvimento sustentável, o será alcançado com a conservação da biodiversidade.

Em Santa Catarina, conforme o estudo de Rosa \& Azevedo (2020), da área total desmatada entre os anos de 1990 e 2008, 87.900 há estão em propriedades privadas com mais de 4 módulos fiscais. Este total representa 25\% de toda área desmatada em propriedades privadas com mais de 4 módulos fiscais 


\section{Considerações Finais}

A aplicação das legislações traz impactos diferenciados sobre as propriedades rurais, sendo que a Lei da Mata Atlântica tem caráter maior de preservação ambiental e, consequentemente, impacta mais fortemente na diminuição das áreas produtivas. Segundo o Código Florestal, podem ocorrer "X - atividades eventuais ou de baixo impacto ambiental" como, por exemplo, a “j) exploração agroflorestal e manejo florestal sustentável, comunitário e familiar, incluindo a extração de produtos florestais não madeireiros, desde que não descaracterizem a cobertura vegetal nativa existente nem prejudiquem a função ambiental da área". Em Áreas de Preservação Permanente (Art. $3^{\circ}$, Art. $8^{\circ}$ ) e "§ $1^{\circ}$ Admite-se a exploração econômica da Reserva Legal mediante manejo sustentável, previamente aprovado pelo órgão competente do Sisnama, de acordo com as

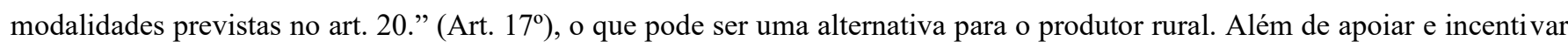
a preservação e recuperação do meio ambiente através de iniciativas como "I - pagamento ou incentivo a serviços ambientais como retribuição, monetária ou não, às atividades de conservação e melhoria dos ecossistemas e que gerem serviços ambientais...", "II - compensação pelas medidas de conservação ambiental necessárias para o cumprimento dos objetivos desta Lei..." e "III - incentivos para comercialização, inovação e aceleração das ações de recuperação, conservação e uso sustentável das florestas e demais formas de vegetação nativa..." o que pode compensar de outras formas a diminuição das áreas produtivas nas propriedades rurais.

Importante destacar que estes impactos, já substanciais, podem ser ainda maiores quando aplicadas integralmente às legislações sobre os limites das propriedades. Para estudos futuros seria pertinente avaliar os impactos dessas legislações sobre as áreas de nascentes, topo de morro e declividades entre 25 e $45^{\circ}$, que se aplicados, possivelmente irão impactar ainda mais social e economicamente os produtores rurais.

\section{Referências}

Antunes, P. B. (2020). Lei da Mata Atlântica ou Lei $n^{o}$ 12.651/2012? http://genjuridico.com.br/2020/05/12/lei-da-mata-atlantica-ou-lei-12-651-2012/.

Brasil. (2012). Lei n. 12.651, de 25 de maio de 2012. Dispõe sobre a proteção da vegetação nativa; altera as Leis nos 6.938, de 31 de agosto de 1981, 9.393, de 19 de dezembro de 1996, e 11.428, de 22 de dezembro de 2006; revoga as Leis nos 4.771, de 15 de setembro de 1965, e 7.754, de 14 de abril de 1989, e a Medida Provisória no 2.166-67, de 24 de agosto de 2001; e dá outras providências. Diário Oficial da União, Brasília, DF, Ano CXLIX, n. 102 , 28 maio 2012. Seção 1, p.1. http://www.planalto.gov.br/ccivil_03/_ato2011-2014/2012/lei/112651.htm.

Brasil. (2006). Ministério do Meio Ambiente (MMA). Lei n. 11.428, de 22 de dezembro de 2006. Dispõe sobre a utilização e proteção da vegetação nativa do Bioma Mata Atlântica, e dá outras providências. Presidência da República, Casa Civil, Subchefi a para Assuntos Jurídicos, Brasília, DF. http://www.planalto.gov.br/ccivil_03/_Ato2004-2006/2006/Lei/L11428.htm.

Freitas, M. W. D. (2013). Estudo integrado e modelagem da dinâmica da paisagem no Alto Uruguai (RS-SC). 119f. Tese (Doutorado em Sensoriamento Remoto) - Instituto Nacional de Pesquisas Espaciais, São José dos Campos, SP. http://mtc-m16d.sid.inpe.br/col/sid.inpe.br/mtcm19/2013/03.27.14.41/doc/publicacao.pdf.

MapBiomas. (2020). Projeto MapBiomas - Coleção [versão] da Série Anual de Mapas de Cobertura e Uso de Solo do Brasil. http://mapbiomas.org.

Bruna Pavão Passos, R, P. \& Klock, A. B. (2019). Análise comparativa do antigo e o Novo Código Florestal: progresso ou retrocesso? Revista Direito Ambiental e sociedade, 9(2), 299-316.

Pereira, A. S., Shitsuka, D. M., Parreira, F. J., \& Shitsuka, R.20 (18). Metodologia da pesquisa Científica. UFSM, NTE. https://repositorio.ufsm.br/bitstream/handle/1/15824/Lic_Computacao_Metodologia-Pesquisa-Cientifica.pdf?sequence=1.

Marcos R. Rosa, M. R., \& Azevedo, T. R. (2020). Nota Técnica o impacto do Despacho no 4.410/2020 do Ministério do Meio Ambiente (MMA). https://mapbiomas-br-site.s3.amazonaws.com/Nota\%20T\%C3\%A9cnica/Nota_T\%C3\%A9cnica_Mata_Atl\%C3\%A2ntica_despacho_4.410_20

20_do_MMA.pdf.

Santa Catarina. (2012). Base Hidrográfica 1:10.000, Secretaria de Estado do Desenvolvimento Econômico Sustentável - SDS/Engemap. Método: Restituição Aerofotogramétrica. http://sigsc.sds.sc.gov.br/.

Santa Catarina. (2012). Ortofoto - (Colorido ou Falsa Cor), 1:10.000. Secretaria de Estado do Desenvolvimento Econômico Sustentável - SDS/Engemap. http://sigsc.sds.sc.gov.br/.

Santa Catarina. (2012). Base Hidrográfica e Ortofoto - (Colorida) 1:10.000. Secretaria de Estado do Desenvolvimento Econômico Sustentável SDS/Engemap. Método: Restituição Aerofotogramétrica. http://sigsc.sds.sc.gov.br/. 
Research, Society and Development, v.10, n.2, e10910212251, 2021 (CC BY 4.0) |ISSN 2525-3409 | DOI: http://dx.doi.org/10.33448/rsd-v10i2.12251

Santa Catarina. (2013). Mapa Político de Santa Catarina (1:500.000): Secretaria de Estado do Planejamento: Diretoria de Geografia e Cartografia.

STF. Supremo Tribunal Federal. http://www.stf.jus.br/portal/cms/verNoticiaDetalhe.asp?idConteudo=445044\#: :text=A\%20AGU\%20sustenta\% 20que $\% 20$ o,acordo\% 20com \%20o \%20tamanho\%20do.

SDS/SC. (2010). Secretaria do Desenvolvimento Econômico Sustentável. Programa de Levantamento Aerofotogramético do Estado de Santa Catarina. http://www.sigsc.sds.sc.gov.br/. 